\title{
Students' Alternative Conceptions Associated With Application of Redox Reactions in Everyday Life
}

\author{
Kenneth Adu-Gyamfi ${ }^{1} \&$ Joseph Ghartey Ampiah ${ }^{1}$ \\ ${ }^{1}$ Department of Science Education, Faculty of Science and Technology Education, College of Education Studies, \\ University of Cape Coast, Cape Coast, Ghana \\ Correspondence: Kenneth Adu-Gyamfi, Department of Science Education, Faculty of Science and Technology \\ Education, College of Education Studies, University of Cape Coast, Cape Coast, Ghana.
}

Received: June 4, 2019

doi:10.20849/aes.v4i1.590
Accepted: June 27, 2019

Online Published: July 1, 2019

URL: https://doi.org/10.20849/aes.v4i1.590

\begin{abstract}
The study explored chemistry students' alternative conceptions associated with application of the processes of oxidation and reduction in real life context. As part of a design-based research approach, a case-study design was followed. Purposive and convenient sampling procedures were employed to select 213 senior high school students to respond to a diagnostic test. Data obtained were analysed using item difficult index, percentages, and themes. The results showed that alternative conceptions existed as preconceived notions, conceptual misunderstanding, and factual misconceptions. It is recommended that chemistry educators should select most appropriate instructional strategies to unearth and address alternative conceptions students may bring to the classroom.
\end{abstract}

Keywords: alternative conceptions, application, redox reactions, students

\section{Introduction}

Redox reactions are one of the interesting chemical concepts with variety of areas to learn in school. However, there are persistent reports of students' difficulties in the concept at the high school level. Those difficulties are of great concern to chemistry educators and researchers. This study is about exploring students' alternative conceptions in applying the processes of oxidation and reduction to real life situations as a way of helping to confront students' difficulties in learning redox reactions.

Issues on conception have been described in diverse forms in the literature. Conception is seen as the way people make theory and hypothesis and think about how they perceive every aspect of the world (Pratt, 1992), and as, a general learning experience (Boulton-Lewis, 2004; Entwistle \& Peterson, 2004). According to Chan (2007), conceptions of learning are the beliefs and understanding students have about learning. In that, students' conceptions are mental models of learning from one academic year to another (Richardson, 2011).

Chan (2007) espoused that students' conceptions of learning can be grouped as quantitative and qualitative conceptions. From Biggs and Moore (as cited in Chan, 2007), the quantitative conception is the quantity of knowledge students acquire and reproduce and qualitative conception is the students' abstraction of meaning and personal change through the process of learning. Saljo's five different conceptions of learning are increase of knowledge; memorising; the acquisition of facts, and procedures, which could be retained and/or utilised in practice; abstraction of meaning; and interpretative process aiming at the understanding of reality (Boulton-Lewis, 2004; Burnett, Pillay, \& Dart, 2003; Kapucu \& Bahcivan, 2014; Richardson, 2011). Saljo's first three groups of conceptions of learning are reproductive conceptions of learning and the next two are reconstructive conceptions of learning (Richardson, 2011).

Burnett et al. (2003) explained that the quantitative and qualitative groups of conceptions of learning are contrasting with deep and surface learning which are built upon meaning making and memorisation. From Boulton-Lewis (2004), Saljo's first three lower categories are all quantitative learning and surface in nature and the next two or three as justified by other studies are all qualitative learning and deep in nature. The lower conceptions are about memorising information and higher conceptions are about making meaning of information. In this study students' conception is the meanings they make of something. 
According to Entwistle and Peterson (2004), Saljo explained that students' conceptions are influenced by specific context and students' conceptions of learning are affected by previous experiences they may have had with teachers and parents (Burnett et al., 2003). It must be noted that how students perceive the context of learning influences their learning strategies and this is open to other interpretations and how students approach learning is influenced by their conceptions (Richardson, 2011). Richardson went further that students' conceptions of learning are relatively stable across a programme of learning.

From Alamdardoo, Moradi, and Dehshiri (2013), there is a strong relationship between all pre-university students' conception of learning and their academic achievement. Additionally, there is a strong relationship between pre-university students' number of conceptions of learning and their academic achievement. Also, Burnett et al. (2003) found that there is a relationship among student self-concept, conceptions of learning, and strategies to learning; where student self-concept mediates between conceptions of learning and strategies to learning. Alamdardoo et al. (2013) inferred from their findings that students' conception of learning make them more flexibly in thinking and active in information processing. The correlation of pre-university students' learning to academic achievement was important review to the current study as it targeted senior high school (SHS) students.

Students' conceptions are given more than one name (Gaitano, Scharfenberg, \& Bogner, 2013; Gonzalez-Espada, 2003; Guest, 2003; Mdachi, 2012; Osman \& Sukor, 2013; Yip, 1998) and one of those names is alternative conceptions. In this study alternative conception was used for its 'gentle' nature on students and the respect it gives to students' conception of concepts. Alternative conceptions are students' ideas different from those accepted and kept by students of all ages and of different origins (Guest, 2003; Hewson, 1992). It must be noted that some alternative conceptions may make sense but are not in line with acceptable scientific explanations. Alternative conceptions are used to show a state in students' learning where they make no meaning of the scientific concepts (Guest, 2003). Consequently, in this study "alternative conceptions are the conceptual difficulties students could have in explaining chemical concepts which end up not being in line with what is accepted in the scientific community" (Adu-Gyamfi, Ampiah, \& Agyei, 2015, p. 745).

There had been more than one attempt to categorise alternative conceptions in the current literature (National Research Council [NRC], 1997; Talanquer, 2006; Yip, 1998). According NRC (1997), alternative conceptions can be grouped into five categories. These categories are:

1. preconceived notions: which are popular students' conceptions based on everyday experiences;

2. nonscientific beliefs: which are students' conceptions developed from sources such as religious and mythical teachings as oppose to science education;

3. conceptual misunderstanding: which are students' conceptions developed from science lessons that fail to help students confront their own preconceived notions and nonscientific beliefs;

4. vernacular misconceptions: which are students' conceptions of scientific words with other meanings in everyday life; and

5. factual misconceptions: which are students' conceptions developed from false ideas learnt at the early ages and have remained unchallenged into the adult age.

It could be deduced from the above that there are a number of sources of alternative conceptions. These include daily life experiences, folklore, curriculum and textbooks, media, language, and school instructions (Chiu, 2005; Gooding \& Metz, 2011; Guest, 2003). Students themselves could be the source of their own alternative conceptions (Gooding \& Metz, 2011) as alternative conceptions are caused by inadequate mental structures with which students learn concepts which are related and these mental structures through stepwise development (Chiu, 2005).

Though Talanquer (2006) gave a caution that the complexity of students' conceptions in chemistry cannot be reduced to a limited number of assumptions and simple reasoning applied in the same way with no consideration for the context, it was necessary for the current study to categorise students' alternative conceptions in everyday application of redox reactions to inform decision on the design of content specific pedagogical content knowledge to confront students' alternative conceptions in redox reactions (if any).

According to Guest (2003), Harlen reported that students' alternative conceptions are built on what they perceive with their senses. That is to say that common-sense reasoning is the source of many alternative conceptions (Talanquer, 2006). For example, wet wood cannot be burnt because it contains water, reduction process results in conversion of compounds to the elements (Chiu, 2005), condensed water on the outside of a glass is the particles 
of water that had filtered through the glass wall (Talanquer, 2006), and in balancing redox reaction in basic medium, $\mathrm{OH}^{-}$ions are added as the system is characteristically basic (Adu-Gyamfi et al., 2015).

Adu-Gyamfi and Ampiah (2019) reported that students conceptualise redox reactions using the combined concept of oxidation number and electron transfer that results in alternative conceptions. For example, "reduction half-reactions involves decrease in oxidation state as a result of loss of electrons" (p. 187). Other examples of alternative conceptions in redox reactions include: in electrochemistry, "electrons travel through solution from one electrode to the other" (Osman \& Sukor, 2013, p. 437); and in balancing redox reactions, $\mathrm{H}_{2} \mathrm{O}$ is added to dilute the acid in the system, $\mathrm{H}_{2} \mathrm{O}$ is added to combine with base, $\mathrm{H}^{+}$is added because the reaction is in acid, and $\mathrm{OH}^{-}$is added to accept proton in basic medium (Adu-Gyamfi et al., 2015).

Students' alternative conceptions could result from lack of critical observation and right follow-up discussion; and improper instruction by parents, teachers, or peers. Teachers should therefore appreciate that alternative conceptions are not naive viewpoints (Wenning, 2008) but a combined concept of common-sense experiences and partly correct scientific information (Gonzalez-Espada, 2003). Students fail to develop correct understanding of basic concepts at the start of their learning and the shortfall can easily disturb any subsequent learning (NRC, 1997). Therefore, there was the need to find out students' alternative conceptions in application of redox reactions for appropriate redress by chemistry educators and researchers. This is because educators and researchers need to identify alternative conceptions if not it would be difficult to address them (Salame, Sarowar, Begum, \& Krauss, 2011) and the best way of identifying alternative conceptions is by the use of diagnostic test (Osman \& Sukor, 2013).

The purpose of the study therefore was to explore chemistry students' alternative conceptions in the application of redox reactions in everyday life. The study was then guided by the research question:

What are the categories of students' alternative conceptions in application of redox reactions in everyday life?

The research question was examined in two sections as; the establishment of the alternative conceptions and the categorisation of the identified alternative conceptions based on the five categories of National Research Council (1997).

\section{Methodology of the Study}

\subsection{Design of the Study}

A case-study design, using both quantitative and qualitative methods, was adopted for the study, as part of a Design-Based Research approach of a major research project. The case study aided the current study to explore students' alternative conceptions in application of redox reactions in everyday life and the categories of such conceptions in relation to NRC (1997) categories of alternative conceptions. The quantitative data was obtained from the scores of students in the two-tier diagnostic test and qualitative data from students' explanations.

\subsection{Sample and Sampling Procedure}

The study was conducted in the Ashanti Region of Ghana. The district assemblies involved in the study were Mampong Municipality, Sekyere Central, and Kwabre East Districts. There were 15 senior high schools in the three district assemblies. The 15 schools were stratified into seven science elective schools and eight non-science elective schools. The elective science schools offered their students subjects such as Biology, Chemistry, Physics, and Mathematics. The elective science schools were purposively selected as their students offer chemistry as one of the electives.

From the seven elective science schools, three were selected through convenient sampling procedure for the study. The three schools could be described as endowed in the category of A, B, and C schools. There were 213 SHS 3 students from the three schools and they all took part in the study as intact groups. The SHS 3 students were selected for the study as they had had lessons on redox reactions at the time of the research.

\subsection{Research Instrument}

The instrument for the study was a two-tier diagnostic test. The test consisted of 18 items of which three were in the area of application of redox reactions in real life. In using the diagnostic test, students selected an option to a test item and provided reasons for the chemistry behind the option selected. The test instrument was validated by comparing the items to the SHS chemistry syllabus, past WAEC chemistry examination questions for SHS, and the literature on chemistry education. The test instrument was given to experts in chemistry education to critique and offer suggestions. The suggestions were used to improve the quality of the instrument and hence, the three test items being reported in this study. 
To ascertain the reliability of the test instrument, the items were subjected to item analysis. During the item analysis, items too easy or difficult were deleted. Thereafter, the KR-20 was calculated. The KR-20 reliability coefficient was calculated as there were unequal item difficult indices for the items (Brennan \& Lee, 2006) and was scored correct or incorrect. Each item scored 2 marks; 1 mark for selection of best option and the other mark for appropriate explanation given. The KR-20 reliability coefficient was calculated as 0.87 .

\subsection{Data Collection Procedure}

Students involved in the study were reassured that their participation in the study was confidential and anonymous, and hence they need not to hesitate in responding to the test instrument. During the first week of the design-based research approach, the 213 students responded to the two-tier diagnostic test. Almost all students used a minimum of 60 minutes to respond to the test.

\subsection{Data Analysis}

The research question was answered in two parts using difficult index, percentages, and themes. The difficult index and percentages helped to establish item difficulty and the students' difficulties in applying the concept of redox reactions. The themes were formed from open coding and constant comparison of the explanations students gave to the selected options of the diagnostic test. After the open coding and constant comparisons, the researchers made meaning of students explanations thereby forming the themes. Sample student statements were added to justify the themes.

\section{Results of Research}

\subsection{Students' Difficulties in Application of Redox Reactions}

Items 1, 2, and 3 diagnosed students' conceptual understanding on the application of oxidation and reduction processes in everyday life. The difficulty indices were $0.4,0.2$, and 0.5 respectively. The results on percentage responses are presented in Figure 1.

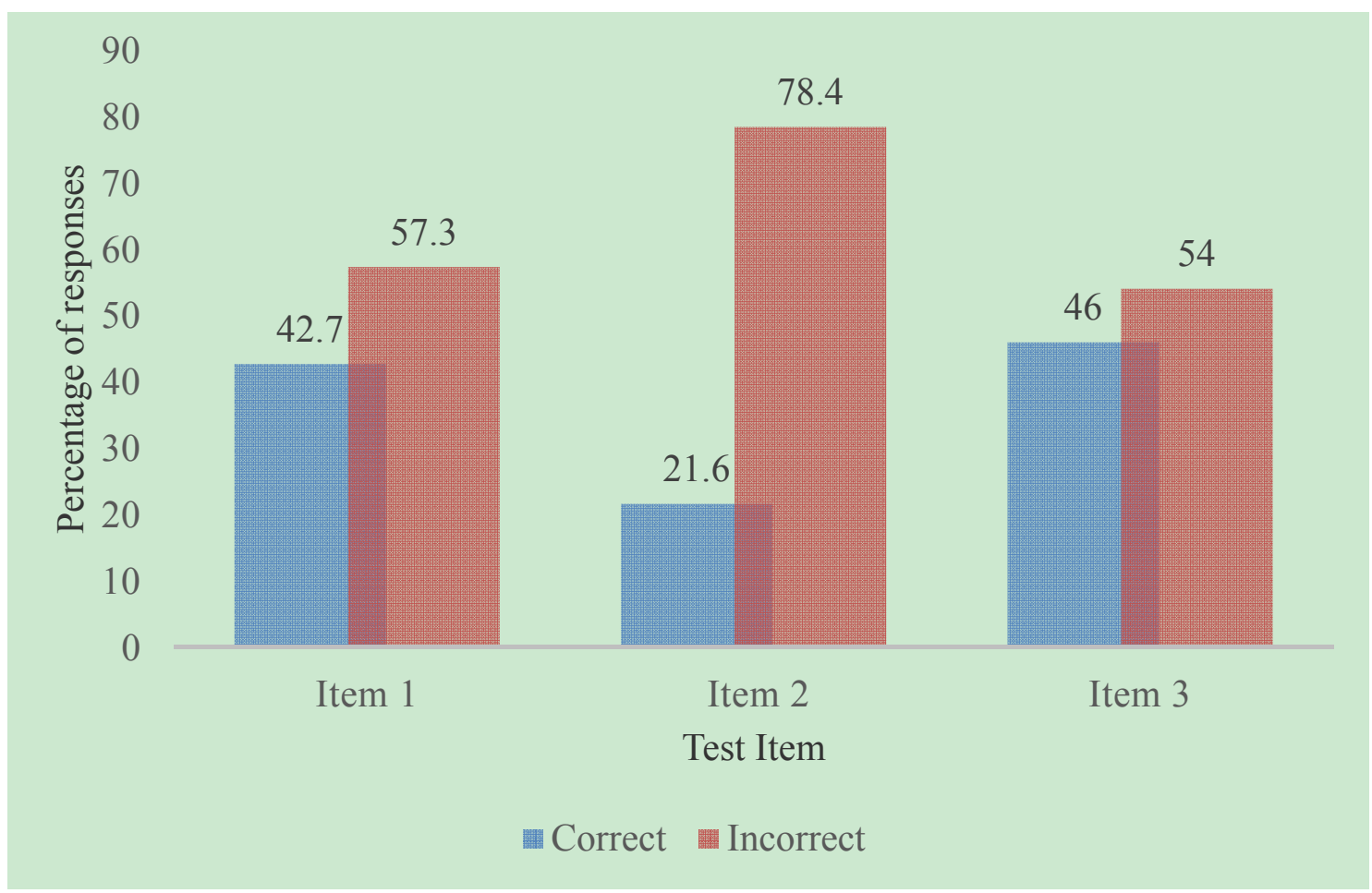

Figure 1. Bar graph illustrating percentage scores in a test

Rusting of metallic iron ship: for Item 3, 46.0\% of the students found it less difficult to identify that the brownish colour developed on a metallic iron ship at the shore of the Atlantic Ocean in the presence of oxygen in an open air and carbonic acid was the result of oxidation and reduction processes. However, $9.9 \%$ identified that 
combustion of iron has occurred, $15.5 \%$ identified that the iron metal has changed colour, and $28.6 \%$ could not even deduce what was going on. As much as oxygen was involved in the reaction does not make it strictly a combustion reaction and even combustion reaction is an example of redox reactions. The change in colour of iron though observable, cannot overshadow the redox reaction taking place on the surface of the metallic iron ship, which is the chemistry behind the change in colour.

Alternative conception: brownish colour was formed on iron metal by addition of hydrogen atoms. An excerpt is: "the brown colour is because a redox reaction has occurred and is because of chemical addition of hydrogen" (210).

Other conceptual difficulties: students had difficulties in conceptualising the role of atmospheric oxygen atoms in rusting of iron. An excerpt is: "a redox reaction has occurred because the oxygen helps in oxidising of iron to break it down to hydrated iron where $\mathrm{CO}_{3}{ }^{2-}$ in $\mathrm{H}_{2} \mathrm{CO}_{3}$ helps to catalyse and reduce the property of the iron" (033).

Students had difficulties in conceptualising combustion as redox reaction. An excerpt is: "combustion reaction has occurred because oxygen supports combustion which changed the colour of the metallic iron" (206).

Students had difficulties in conceptualising rusting of iron as redox reaction as rusting was considered as a physical change. An excerpt is: "iron metal has changed colour because there is the presence of rusting" (151).

Reaction of copper envelope and frame: For Item 1, 42.7\% of the students correctly identified that oxidation and reduction processes occurred when an envelope of copper metal was heated with a flame to turn black on the outside while the inside remained copper-coloured. However, $24.9 \%$ identified that a combustion reaction has occurred, 3.8\% identified that the outside of copper was made from black soot, $2.8 \%$ identified that the copper atom has changed colour when the envelop was heated, and $25.8 \%$ of the students could not provide any response as to what happened when copper envelope was heated with a flame. In the case of Barke (2012), most of the students identified the reaction as a black soot being formed from the outside of the copper envelop, which was the detractor to the redox reaction taking place as compared to the current study. The presence of the flame once again could have attracted the attention of the students thinking that combustion was taking place. This is an obvious lack of conception of the role of oxygen made students accept the black soot as actually what was happening instead of redox reaction.

Alternative conceptions: in combustion, the presence of heat introduces oxygen atoms. An excerpt is: "combustion reaction has occurred because the flame outside the copper metal added oxygen" (077).

Black soot from frame changes the colour of copper metal black. An excerpt is: "the outside was made from black soot because the outside copper the smoke of the flame is black. It will dust the outside of the copper" (178).

Copper metal changes colour when it loses electrons. An excerpt is: "this is because copper lost electron and then changed colour" (153).

Copper metal turning black in a frame is due to transfer of hydrogen atoms. An excerpt is: "A redox reaction has occurred because there was an addition of hydrogen as reduction and there was removal of hydrogen as the oxidation" (175).

Other conceptual difficulties: students had difficulties in conceptualising that addition of oxygen to substances causing combustion is a form of redox reactions and not just combustion. An excerpt is: "combustion reaction has occurred because it was burnt in the presence of oxygen" (051).

Students had difficulties in conceptualising copper metal heated in a frame as redox reactions using oxygen transfer but not release of electrons or increase in oxidation state of copper. An excerpt is: "a redox reaction has occurred since oxygen has been added to the copper metal as oxidation" (066).

Students faced difficulties in identifying and explaining oxidation and reduction processes as simultaneous processes. An excerpt is: "a redox reaction has occurred because both oxidation and reduction occurred simultaneously to balance each other thereby maintaining the colour of the copper metal" (113).

Production of iron in blast furnace: For Item 2, only $21.6 \%$ of the students found it less difficult to identify that the production of iron in the blast furnace involving iron oxide and coal was redox reaction. However, $14.1 \%$ of the students identified that carbon was a catalyst in the reaction, $26.8 \%$ of the students identified that the iron oxide has simply reduced, $9.4 \%$ of the students identified that the iron oxide has simply decomposed into its elements, and $28.2 \%$ even failed to provide any response. The percentage of the students who appreciated that the production of iron in the blast furnace was almost the same as that reported by Barke (2012), which is $20.0 \%$. 
This could also be the case where students were being distracted by the presence of oxygen, thinking that it is taking away from the iron oxide thereby reducing it to metallic iron and carbon dioxide or just carbon.

Alternative conceptions: carbon as a catalyst in a blast furnace reduces iron oxide by removal of oxygen atoms. An excerpt is: "the carbon as a catalyst reduces $\mathrm{Fe}_{3} \mathrm{O}_{4}$ by removing its oxygen" (008).

Iron in the iron oxide increased in oxidation state to form iron metal. An excerpt is: "a redox reaction has occurred because iron has gain in the oxidation number" (141).

Iron in blast furnace reduced by loss of electrons. An excerpt is: "the iron has reduced because iron oxide has decreased in electrons ..." (128).

Iron oxide lost oxygen atoms to form iron metal in blast furnace. An excerpt is: "oxygen is removed in the iron oxide to produce only the iron, so redox reaction has occurred" (101).

Iron oxide was oxidised by carbon to form iron metal. An excerpt is: "a redox reaction has occurred because the iron oxide $\left(\mathrm{Fe}_{3} \mathrm{O}_{4}\right)$ is being oxidised by the carbon into liquid iron" (207).

Iron oxide reduced in blast furnace as it changed its physical state. An excerpt is: "because iron oxide has changed from its original state to another iron oxide has lost it property as a metal to another state" (053).

Iron oxide reduced by the presence of glaring light. An excerpt is: "iron oxide has reduced; because the iron is running out with glaring means, the iron oxide has reduced" (182).

Other conceptual difficulties: students had difficulties in conceptualising production of iron in blast furnace as oxidation and reduction processes because of the role of carbon. An excerpt is: "carbon was a catalyst; because addition of a suitable catalyst increases the rate of every reaction" (011).

Students had difficulties in identifying and explaining the atoms (species) that lost electrons in the blast furnace. An excerpt is: "a redox reaction has occurred because of the removal of an electron from a substance has occurred" (083).

Students had difficulties in conceptualising decomposition as redox reactions. An excerpt is: "iron oxide has decomposed into elements since the iron in the blast furnace is iron oxide and the coal (carbon) is necessary by heating" (162).

\subsection{Categories of Students' Alternative Conceptions in Application of Redox Reactions}

To categorise students' alternative conceptions in the application of redox reactions in relation to the five categories of NRC (1997); preconceived notions, non-scientific beliefs, conceptual misunderstanding, vernacular misconceptions and factual misconceptions, 30 alternative conceptions were simple randomly selected. The results on frequency of occurrences are presented in Figure 2. 


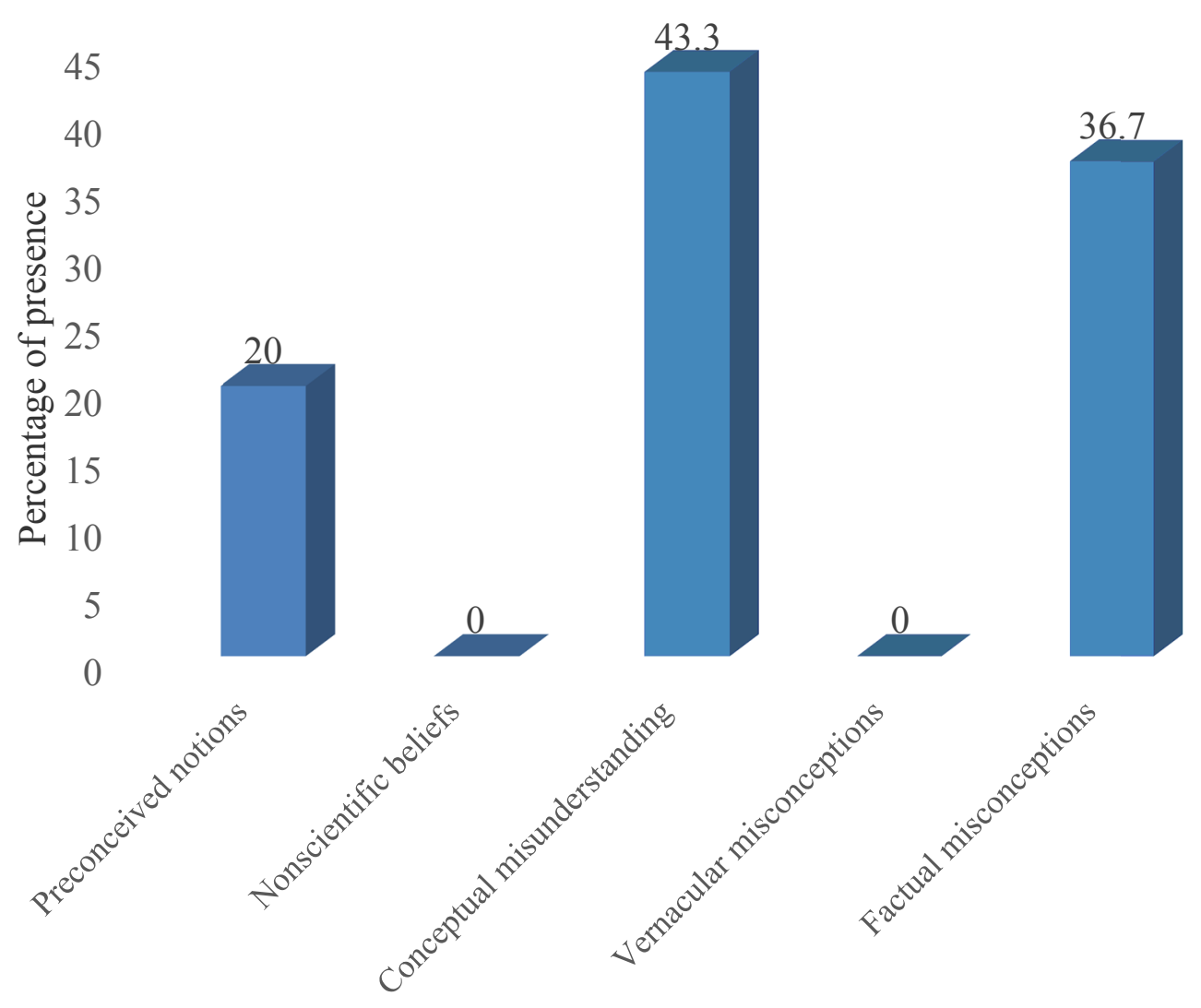

\section{Categories of alternative conceptions}

Figure 2. Bar graph illustrating percentage presence of alternative conceptions

The results from Figure 2 showed that of the five categories, two were absent and others were present. The students' alternative conceptions in application of redox reactions were not in the categories of nonscientific beliefs and vernacular misconceptions. Majority (43.3\%) of students' alternative conceptions in application of redox reactions were present as conceptual misunderstanding. The excerpts are:

"the carbon as a catalyst reduces $\mathrm{Fe}_{3} \mathrm{O}_{4}$ by removing its oxygen" (008).

"a redox reaction has occurred because there was an addition of hydrogen as reduction and there was removal of hydrogen as the oxidation" (175).

"the brown colour is because a redox reaction has occurred and is because of chemical addition of hydrogen" (210).

With respect to factual misconceptions, $36.7 \%$ of the students" alternative conceptions were present. The excerpts are:

"a redox reaction has occurred because the oxygen helps in oxidising of iron to break it down to hydrated iron where $\mathrm{CO}_{3}{ }^{2-}$ in $\mathrm{H}_{2} \mathrm{CO}_{3}$ helps to catalyse and reduce the property of the iron" (033).

"a redox reaction has occurred since oxygen has been added to the copper metal as oxidation" (066).

"oxygen is removed in the iron oxide to produce only the iron, so redox reaction has occurred" (101).

With respect to preconceived notions, $20.0 \%$ of the students' alternative conceptions were present. The excerpts are:

"iron metal has changed colour because there is the presence of rusting" (151).

"the outside was made from black soot because the outside copper the smoke of the flame is black. It will dust the outside of the copper" (178). 
"iron oxide has reduced; because the iron is running out with glaring means, the iron oxide has reduced" (182).

\section{Discussion}

The results, in relation to the development of rust on the surface of metallic iron being redox reaction, showed that most of the students could not even associate the reaction with transfer of electrons. Even where the concept of oxidation number was used, some of the students found it difficult to explain the concept. The difficulty of students was their preference for the concept of transfer of oxygen, and not considering combustion as redox reaction. Though such students in the study usually deduced the correct response, they could not explain the chemistry very well. This is because, not all redox reactions are caused by transfer of oxygen, notwithstanding the presence of oxygen atoms in species involved in some reactions.

In addition, students had difficulties in applying the concept of redox reactions in burning of copper metal in a frame. This is because there were very few instances where students correctly conceptualised that redox reaction had occurred in the given process. Even with the idea that redox reaction has occurred, only few of the students' explanations could be related to change in oxidation state and transfer of electrons. Copper lost two electrons, which is oxidation and the oxygen atom accepted the two electrons, which is reduction or the oxidation number of copper increased from 0 to +2 , which is oxidation and the oxidation number of oxygen decreased from 0 to -2 , which is reduction.

The results further showed the difficulty of the students was their understanding of the heat from the flame, which they conceptualised that it introduced oxygen atom to oxidise the outside of copper to form an oxide of copper. This shows that the students' understanding of the role of oxygen in combustion is not clear (Barke, 2012). The process of copper metal turning black on the outside as a result of being heated was considered as physical but not a chemical process. This is not the correct chemistry. This was because the formation of the black colour was not just the deposition of soot. Though students realised that copper had lost electrons in the process they could not conceptualise the process as redox reactions. This was an indication that the students had difficulties in everyday application of the concept of redox reactions. These alternative conceptions and other conceptual difficulties demonstrated by students were as a result of simplistic association of chemical concepts (Talanquer, 2006).

As much as it was true that the carbon (coal) was the catalyst in the reaction, it cannot be considered as the main reason for the reaction. This is because the reaction would have occurred without the catalyst and hence iron was produced from iron oxide in the blast furnace by a certain chemistry which needed to have been explained instead of the catalysis aspect. Though the iron from the iron oxide reduced to form the iron metal, it is not necessarily by means of transfer of oxygen, change of physical state, decomposition into elements, or the given out of glaring light. The reduction is as a result of transfer of electrons, which induces the change in oxidation state of iron. This then places the process in redox reaction but not just reduction. This is because wherever there is reduction process there is a simultaneous oxidation process. Hence, the students' alternative conceptions and other conceptual difficulties here were how to explain that the reduction of iron results in the oxidation of carbon with the oxygen from the injected air leading to the production of the iron metal in the blast furnace.

Alternative conceptions were present in the application of redox reactions by students and this is consistent with previous studies (Adu-Gyamfi et al., 2015; Osman \& Sukor, 2013) that have identified alternative conceptions in redox reactions. Generally, the report of NRC (1997) made five categorisations of students' alternative conceptions, however, the current study has showed that in the application of redox reactions not all categories are present. The alternative conceptions in the application of redox reactions were preconceived notions, conceptual misunderstanding, and factual misconceptions but not vernacular misconceptions and nonscientific beliefs. This could mean that everyday life meaning of scientific concepts, religion and myth have little or no impact on development of alternative conceptions in application of redox reactions among chemistry students. The alternative conceptions relating to application of redox reactions were those that classroom instruction has failed to help students confront to change them.

\section{Conclusions}

There are alternative conceptions associated with the application of redox reactions in everyday life. The current study has contributed to the literature that alternative conceptions associated with application of redox reactions are preconceived notions, conceptual misunderstanding, and factual misconceptions. These findings would help chemistry educators in general and specifically, those teaching redox reactions to appreciate the nature of students' alternative conceptions fronting learning this important aspect of chemistry at the high school level and to help deal them. Hence, as most of the alternative conceptions were developed from science (such as chemistry) lessons, it is, therefore, recommended that chemistry educators and researcher should design and develop 
instructions that will help to challenge students' alternative conceptions for possible elimination. And chemistry educators are also encouraged to select the most appropriate instructional strategies that can unearth the alternative conceptions to address them in a lesson.

\section{References}

Adu-Gyamfi, K., \& Ampiah, J. G. (2019). Chemistry students' difficulties in learning oxidation-reduction reactions. Chemistry: Bulgarian Journal of Science Education, 28(2), 180-200.

Adu-Gyamfi, K., Ampiah, J. G., \& Agyei, D. D. (2015). High school chemistry students' alternative conceptions of $\mathrm{H}_{2} \mathrm{O}, \mathrm{OH}^{-}$, and $\mathrm{H}^{+}$in balancing redox reactions. International Journal of Development and Sustainability, $4(6), 744-758$.

Alamdardoo, G. H., Moradi, S., \& Dehshiri, G. R. (2013). The relationship between students' conception of learning and their academic achievement. Psychology, 4(1), 44-49.

Barke, H.-D. (2012). Two ideas of the redox reaction: Misconceptions and their challenges in chemistry education. African Journal of Chemical Education, 2(2), 32-50.

Boulton-Lewis, G. M. (2004). Conceptions of teaching and learning at school and university: Similarities, differences, relationships, and contextual factors. European Journal of School Psychology, 2(1-2), 19-38.

Brennan, R. L., \& Lee, W.-C. (2006). Some perspectives on KR-21. Iowa City, IA: Centre for Advanced Studies in Measurement and Assessment.

Burnett, P. C., Pillay, H., \& Dart, B. C. (2003). The influences of conceptions of learning and learners self-concept on high school students' approaches to learning. School Psychology International, 24(1), 54-66.

Chan, K.-W. (2007). Hong Kong teacher education students' epistemological beliefs and their relations with conceptions of learning and learning strategies. The Asia Pacific-Education Researcher, 16(2), 199-214.

Chiu, M.-H. (2005). A national survey of students' conceptions in Chemistry in Taiwan. Chemical Education International, 6(1), 1-8.

De Jong, O., \& Treagust, D. (2002). The teaching and learning of electrochemistry. In J. K. Gilbert, O. De Jong, R. Justi, D. F. Treagust, \& J. H. van Driel (Eds.), Chemical education: Towards research-based practices (pp. 317-337). Dordrecht: Kluwer Academic Publishers.

De Jong, O., Acampo, J., \& Verdonk, A. (1995). Problems in teaching the topic redox reactions: Actions and conceptions of chemistry teachers. Journal of Research in Science Teaching, 32(10), 1097-1110.

Entwistle, N. J., \& Peterson, E. R. (2004). Conceptions of learning and knowledge in higher education: Relationships with study behaviour and influences of learning environments. International Journal of Educational Research, 41, 407-428.

Gaitano, F., Scharfenberg, F.-J., \& Bogner, F. X. (2013). Investigation of students' alternative conceptions of terms and processes of technology. International Scholarly Research Notices Education, 1-12.

Gonzalez-Espada, W. J. (2003). A last chance for getting it right: Addressing alternative conceptions in the physical sciences. The Physics Teacher, 41, 36-38.

Gooding, J., \& Metz, B. (2011). From misconception to conceptual change. Tips for identifying and overcoming students' misconceptions. The Science Teacher, 78(4), 34-37. Retrieved from static.nsta.org/files/tst1104_34.pdf

Guest, G. (2003). Alternative frameworks and misconceptions in primary science. Bristol: UWE.

Hewson, P. W. (1992). Conceptual change in science teaching and teacher education. Meeting on Research and Curriculum Development in Science Teaching, under the auspices of National Centre for Educational Research, Development, and Assessment, Ministry of Education, Madrid.

Kapucu, S., \& Bahcivan, E. (2014). The differences in senior Turkish pre-service elementary science teachers' conceptions of learning science with respect to gender and socio-economic status. International Online Journal of Educational Science, 6(1), 41-48.

Mckenney, S., \& Reeves, T. (2012). Conducting educational design research. London: Routledge.

Mdachi, S. J. M. (2012). Giving thought to students' alternative conceptions in stereochemistry: One teacher's basis for pedagogical content knowledge improvement. Journal of Turkish Science Education, 9(4), 22-34. 
National Research Council (NRC). (1997). Chapter 4: Misconceptions as barriers to understanding science. In Science teaching reconsidered: A handbook. Washington, DC: The National Academies Press. Retrieved from www.nap.edu/read/5287/chapter/5

Osman, K., \& Sukor, N. S. (2013). Conceptual understanding in secondary school chemistry: A discussion of the difficulties experienced by students. American Journal of Applied Sciences, 10(5), 433-441.

Osterlund, L.-L., \& Ekborg, M. (2009). Students' understanding of redox reactions in three situations. Nordina, $5(2), 115-127$.

Pratt, D. D. (1992). Chinese conceptions of learning and teaching: A westerner's attempt at understanding. International Journal of Lifelong Education, 11(4), 301-319.

Richardson, J. T. E. (2011). Approaches to studying, conceptions of learning and learning styles in higher education. Learning and Individual Differences, 21(3), 288-293.

Salame, I. I., Sarowar, S., Begum, S., \& Krauss, D. (2011). Students' alternative conceptions about atomic properties and the periodic table. The Chemistry Educator, 16, 190-194.

Talanquer, V. (2006). Commonsense chemistry: A model for understanding students' alternative conceptions. Journal of Chemical Education, 83(5), 811-816.

Wenning, C. J. (2008). Dealing more effectively with alternative conceptions in science. Journal of Physics Teacher Education Online, 5(1), 11-19.

Yip, D.-Y. (1998). Alternative conceptions on excretion and implications for teaching. Educational Journal, 26(1), 101-116.

\section{Copyrights}

Copyright for this article is retained by the author(s), with first publication rights granted to the journal.

This is an open-access article distributed under the terms and conditions of the Creative Commons Attribution license (http://creativecommons.org/licenses/by/4.0/). 